low. Cases due to drugs or unknown causes are more diffcult to treat and carry a fairly high mortality. Steroids are usually given in these cases and sometimes appear to be life-saving, but as resolution is so swift once the toxaemic stage has passed their real value is difficult to assess. Expert nursing care is of paramount importance.

Lyell, A., British fournal of Dermatology, 1956, 68, 355.

Lyell, A., British Fournal of Dermatology, 1967, 79, 662.

Samuels, M. J., British Fournal of Dermatology, 1967, 79, 672.

Jefferson, J., British Medical fournal, 1967, 2, 802.

Selish, M. E., and Glasgow, L. A., Fournal of Pediatrics, 1971, 78, 958.

-Melish, M. E., and Glasgow, L. A., New England fournal of Medicine, $1970,282,1114$

\section{Prognosis of Gastric Cancer}

The outlook in carcinoma of the stomach is bad because most cases are too advanced at the time of diagnosis for complete resection. Between 5 and $11 \%$ of all cases survive for five years, ${ }^{1} 2$ but with radical surgery the survival rate increases-in one series to $18.4 \%^{3}$ and in another to over $25 \% .^{2}$ Occasionally patients with gastric cancer survive many years without treatment or after an incomplete removal of the tumour. ${ }^{4}$ The prognosis after radical resection is influenced by the extent of involvement of the lymph nodes, for metastasis is associated with a greatly decreased life expectancy. In one series of cases a $50 \%$ five-year survival rate in gastric cancer without lymph-node involvement was reduced to $15-20 \%$ when the patients had metastases. ${ }^{4}$

The site of the tumour also has a bearing on the prognosis: the more distal the lesion the better the outlook. In another series of cases carcinoma of the cardia was associated with a $9 \cdot 2 \%$ five-year survival rate, while $16.1 \%$ of patients with carcinoma of the pylorus lived for five years. ${ }^{3}$ A paradoxical feature is the tendency for patients with a long history of symptoms before treatment to have a better prognosis than those in whom the duration of symptoms has been short. The explanation appears to be the slowlygrowing nature of the type of tumour that causes longstanding symptoms. It is this type of carcinoma that is most eligible for radical resection. ${ }^{2}$ is

Recently A. Paile has assessed the prognosis of gastric carcinoma histologically. ${ }^{6} \mathrm{He}$ studied 152 resected stomachs and 98 lymph nodes, gauging the prognosis in terms of survival for up to five years after resection. He found that the most important prognostic guide was the depth of penetration of the stomach wall by the tumour. There was a $50 \%$ five-year survival rate when the tumour was confined to the submucosa, but this fell to $20 \%$ when the muscle coat had been penetrated. The presence of mucus secretion in the tumour affected the outlook adversely, and was associated with a five-year survival rate of less than half of that in patients with tumours that did not secrete mucus. A third important prognostic indicator was the intensity of the lymphocytic infiltration in the stroma: the heavier the infiltration the better the prognosis.

Detailed studies of the tumour cells showed that a copious cytoplasm relative to the size of the nucleus, considerable mitotic activity, and small, inconspicuous nucleoli characterized the type of cell associated with more malignant tumours, whereas cells with scanty cytoplasm, slight mitotic activity, and large nucleoli indicated a better prognosis.
These cytological features were, however, of less importance than the three grosser histological criteria.

Paile noted that the degree of glandular differentiation had no prognostic significance. Neither was the intensity of the plasma-cell infiltration in the stroma or the regional lymph nodes important. This would appear to confirm the primacy of cell-mediated (lymphocytic) immunity in the resistance to cancer. Immunoglobulins, produced by plasma cells, play no significant part.

On the strength of these findings Paile has suggested a tabulated scheme for assessing the prognosis of stomach cancer-the criteria used being the depth of penetration, the presence or absence of mucus secretion, and the degree of lymphocytic infiltration. While these prognostic features are of value in assessing an individual case of gastric carcinoma, it is the absence of early diagnostic indicators that is the most serious problem in this disease at present. What is urgently needed is a method for detecting the more malignant type of cancer early enough for it to be completely removed.

1 Avery Jones, F., Gummer, J. W. P., and Lennard-Jones, J. E., in Clinical Gastroenterolog $v$, 2nd ed. 375 , Oxford, Blackwell, 1968

Flood, C. A., Wells, J., and Harvey, H. D., American fournal of Digestive Diseases, $1962,7,420$.

s Brooks, V. S., Waterhouse, J. A. H., and Powell, D. J., British Medical fournal, S., Waterhouse,

Fournal, 1965, 1, 1577.
Pygott, F., Gut, 1964, 5, 118 .

5 Swynnerton, B. F., and Truelove, S. C., British Medical fournal, 1952, 1,

- Paile, A., Annales Chirurgiae et Gynaecologiae Fenniae, 1971, 60, Suppl. 175.

\section{Puff of Smoke}

Between 1965 and 1968 T. Kudo ${ }^{2}$ and A. Nishimoto and S. Takeuchi $^{3}$ described a remarkable radiological appearance seen in Japanese children who had developed evidence of sudden cerebrovascular insufficiency. Arteriography showed an apparent occlusion at the termination of the internal carotid artery (and in some cases the basilar artery), where the normal vascular pattern was replaced by a filmy network of small vessels, streaming upwards like smoke rising from a cigarette. The rather attractive name of "moyamoya disease" was suggested for this, ${ }^{4}$ moyamoya being the Japanese word for puff of smoke.

At that time the cases appeared to be confined to Japanese patients, and though several cases were described from America these were also of Japanese origin. But gradually other cases came to be described in Europeans, ${ }^{5}$ and the condition has now been seen in many countries, 6 including Great Britain. ${ }^{7}$ The patients have been mainly female, and in children they have usually presented as one of the forms of "acute hemiplegia in childhood." The diagnosis is essentially by arteriography. At first these cases were thought to represent angiomata, and the word "telangiectasia" is frequently used, 6 but it is gradually becoming accepted that what the radiography shows is a collateral circulation. It has even been suggested that these collaterals represent the persistence of, or opening up of, the "rete mirabile" seen in certain lower animals. ${ }^{4}$

Why the normal vascular pattern is deficient is uncertain. Congenital hypoplasia has been suggested in many cases, for it may be bilateral and has been recorded in siblings, ${ }^{4}$ but other workers have believed it to show progression and to represent a progressive occlusive arteritis. ${ }^{8}$ In either event 